\title{
Investigation of Appearance Anxiety and the Gender Role in Women's Sports Except for Social Gender Norms
}

\section{Gulsum Bastug ${ }^{1}$ \\ Taner Yilmaz ${ }^{2}$ \\ Erkan Bingol ${ }^{3}$ \\ Ilker Gunel ${ }^{4}$}

${ }^{1,3}$ Mugla Universty, Faculty of Sports Science, Mugla, Turkey.

Email: gbastug@mu.edu.trTel:05057676029

'Email:bingolerkan@gmail.com Tel:05547291379

Usak Universty, Faculty of Sports Science, Usak, Turkey.

'Email:taner.yilmaz@usak.edu.trTel:05327765765

"Provincial Directorate of Youth and Sports, Antalya, Turkey.

‘Email:kergunel@gmail.comTel:05072624357

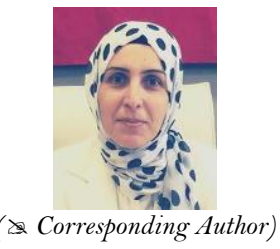

( Corresponding Author)

Abstract

The Bem Sex-Role Inventory (BSRI), conducted by Hart et al. (2008) and adapted to Turkish by Dogan as Social Appearance Anxiety Scale (SAAS) (Dogan, 2010) was used in our study. In the analysis of the data, t-test and ANOVA test were used. As a result; There was a significant difference between female athletes' hormone use variable and appearance anxiety and gender role $(\mathrm{p}<0.05)$. It was determined that female athletes using hormone had appearance anxiety. A significant difference was found between maternal educational status and appearance anxiety and gender role. A significant difference was found between the paternal education status variable and the masculine gender role. A significant negative correlation was found between the age variable and appearance anxiety of female athletes. There was a positive relationship between appearance anxiety and masculine gender role. When the gender role values increase the values of appearance anxiety increase. It is recommended that special contact with women athletes who go beyond the social gender norms should be established according to expert opinions and all actors such as sports managers, trainer, sportsman, referee, physical education teacher etc. should be informed. In order to increase the proportion of women engaged in sports in the society, to support the girls who are new to the sports and not to create false opinions about the sportswomen, it is recommended to put forward the role models suitable for the female athlete profile.

Keywords: Female athletes, Perception of appearance, Gender role.

Citation | Gulsum Bastug; Taner Yilmaz; Erkan Bingol; Ilker Gunel (2019). Investigation of Appearance Anxiety and the Gender Role in Women's Sports Except for Social Gender Norms. Asian Journal of Education and Training, 5(4): 526-530.

History:

Received: 12 July 2019

Revised: 19 August 2019

Accepted: 30 September 2019

Published: 6 November 2019

Licensed: This work is licensed under a Creative Commons

Attribution 3.0 License $(\mathrm{cc})$ )

Publisher: Asian Online Journal Publishing Group
Acknowledgement: All authors contributed to the conception and design of the study.

Funding: This study received no specific financial support

Competing Interests: The authors declare that they have no conflict of interests.

Transparency: The authors confirm that the manuscript is an honest, accurate, and transparent account of the study was reported; that no vital features of the study have been omitted; and that any discrepancies from the study as planned have been explained.

Ethical: This study follows all ethical practices during writing.

\section{Contents}

1. Introduction

References. 


\section{Contribution of this paper to the literature}

This study contributes to existing literature by examining the female athletes who are out of gender norms. In the literature, there are very few studies on gender norms, female athletes have a male-specific appearance, and the attitudes and behaviors of women athletes that we are not familiar with are the basis of this study.

\section{Introduction}

Gender refers to the genetic, biological, physiological characteristics and differences of the individual as female or male (Cherry, 2005). Gender is socio-cultural which points to masculine and feminine qualities, behavioral patterns, roles, responsibilities (Bhasin, 2003). In modern societies, sport plays an important role in the formation of gender roles in both men and women. The male body is accustomed to behaviors such as hardness, endurance, and combat being disciplined through men's sports such as boxing, wrestling, karate, football and males who do not or cannot participate in such behavior are excluded and subordinated (Sancar, 2013). For female students, it is seen that they are not accepted as normal when they prefer to participate in football and basketball, which are deemed appropriate for men, rather than gymnastics and volleyball which are deemed appropriate (Koca and Demirhan, 2005). Women athletes other than gender norms are exposed to labeling and negative judgment of the society such as "masculine" or "lesbian" “(Koca, 2006; Kleindienst-Cachay and Heckemeyer, 2008). Nowadays, even if women's participation in different forms of sports increases, traditional female roles and the meaning attached to the female body; beautiful, elegant naive and aesthetic elements are more acceptable to turn to sports branches (Kavasoğlu and Yaşar, 2016). Gymnastics, plates, step-aerobic, volleyball, swimming, ice skating, tennis, and walking are regarded more suitable for women in our country while football, basketball, boxing, wrestling, and weightlifting are regarded as more suitable sports for men (Koca and Demirhan, 2005). Turkey is seen to be socialized in traditional gender roles (Imamoĝklu and Karakitapoĝklu-Aygüun, 2004; Imamoğlu and Karakitapoğlu-Aygün, 2006). Individuals strive to make a more effective impression on other people and look attractive. Most people want to communicate more with attractive individuals (Yousefi et al., 2009). This is defined as self-presentation or impression management. The individual who thinks that he/she cannot make a good impression on other people is experiencing anxiety (Leary et al., 1988). According to Harter (1983) the feelings of the person about his appearance, that is his physical respect, is the most important factor affecting the whole selfesteem. The significance paid attention to the appearance and assessment about appearance may vary depending on the time and culture of the society. According to Hart et al. (2008) the notion of social appearance anxiety, including the body image and body image, such as skin color, facial shape (nose, eyes distance, smile, etc.) of the individual, beyond the general physical appearance such as height, weight and muscle structure; is a comprehensive concept. Social appearance anxiety can be considered as a result of the negative body image of the individual's body and appearance. Most socially anxious people have negative beliefs about their value and importance as in depression. However, as in the case of depressed individuals, these beliefs are not continuous in socially anxious individuals, and when they do not perceive threats from others, they become very positive thoughts towards the self when they are alone (Clark and Wells, 1995). In a study examining the relationship between self-esteem, social appearance anxiety, depression, and anxiety among women in adolescence and young adulthood, a significant relationship was found between social anxiety level and self-esteem (Ozcan et al., 2013). It was found that participation in sports was an important factor in gender structure and that most of the athletes had androgynous (femininity and masculinity score 15) and masculine gender roles (Koca et al., 2005). Androgynous gender role is defined as the role of gender in which both the feminine and masculine characteristics of the individuals exhibit together and at different degrees (Mayer and Sutton, 1996). It has been found that individuals who exhibit androgynous gender roles exhibit both masculine and feminine characteristics at a high level, are more flexible and can exhibit more gender-matched behaviors in different settings (Dökmen, 2004). Baştuğ (2011) said that athletes' body perception levels were examined, the features of physical competence orientation, health orientation, appearance evaluation, fitness evaluation, health evaluation, and body areas satisfaction were found to be higher than non-athletes'. Athletes care about health, appearance and physical competence, are satisfied with their body parts because of their muscular body structures developing due to exercises, and they have a flexible personality to show feminine and masculine features that the environment needs in terms of gender roles. That women athletes show dominant, strong, ambitious, aggressive features in sports environments and traditional feminine roles out of sports environments bring them closer to androgynous (both feminine and masculine) or male gender roles. Competition, power, and desire to win are seen as women athletes moving away from feminine traits and exhibiting their attitudes towards men. Perhaps sports is seen as a social space in which the behaviors other than those social norms in women gain meaning. The fact that women athletes have a male-specific appearance and attitudes and behaviors that we are not used to seeing in women athletes are the most remarkable elements in sports environments. Based on these observations, it is aimed to examine the female athletes except the perception of appearance and gender norms.

\section{Material and Method}

83 female athletes with a mean age of $19.98 \pm 1.44$ were included in the study. To determine the perceptions of the athletes participating in the research on gender roles, the Bem Sex-Role Inventory (BSRI), conducted by Hart et al. (2008) and adapted to Turkish by Dogan as Social Appearance Anxiety Scale (SAAS) (Dogan, 2010) was used. In the analysis of the data, t-test and ANOVA test were used.

The Bem Sex-Role Inventory, which was developed by Bem $(1974 ; 1975)$ to evaluate the gender roles, has 20 adjectives showing the feminine and masculine characteristics. The total scores obtained from the femininity $(\mathrm{F})$ and masculinity (M) scales are evaluated according to the median of the group and individuals are classified according to the four gender roles (feminine, masculine, androgynous and uncertain). Accordingly, the classification is; the femininity score is below the feminine median, but the masculinity score is above the masculinity median is called as masculine; the femininity score is above the feminine median but the masculinity 
score is below the masculinity median is called as feminine; the femininity score is above the feminine median and the masculinity score is above the masculinity median is called as androgynous; The femininity score is below the feminine median and the masculinity score is below the masculinity median is called as uncertain. Turkish adaptation of BSRI was made by Kavuncu (1987). The test-retest reliability coefficient $(\mathrm{n}=208)$ of the Turkish version of BSRI was found to be .75 for $\mathrm{F}$ and .89 for M (Kavuncu, 1987). Also in the criterion validity study conducted by Dökmen (1991). Significant relationships were found between BSRI and Gender Role Scale about Gender Roles (for $\mathrm{F}, \mathrm{r}=.51 ; \mathrm{r}=.63$ for $\mathrm{M}$ ).

Social Appearance Anxiety Scale-SAAS, being a 16-item 5-point Likert-type scale, was developed by Hart et al. (2008). The scale of social appearance anxiety is composed of cognitive, emotional and behavioral expressions related to the individual's appearance anxiety. The increase in the score obtained from the scale is considered as an indicator of the decrease in self-esteem. The Turkish validity and reliability study of the scale was performed by Dogan (2010). In the study conducted with 340 students, the internal consistency coefficient of the scale was 0.93 and the reliability coefficient calculated by the test-retest method was 0.85 . According to the result of exploratory factor analysis (EFA) to determine the structural validity of the SAAS, Factor loads related to the items of the scale ranged between .35 and .87 . In the analysis of the data, t-test and ANOVA test were used.

\section{Findings}

\begin{tabular}{|c|c|c|c|c|c|c|c|}
\hline Variables & \multicolumn{2}{|c|}{ Do you use hormones? } & $\mathbf{N}$ & $\bar{X}$ & Sd. & $\mathrm{t}$ & $\bar{p}$ \\
\hline \multirow{2}{*}{ Appearance anxiety } & & Yes & 7 & 45,00 & 23,85 & \multirow{2}{*}{2,173} & \multirow{2}{*}{,033 } \\
\hline & & No & 76 & 33,14 & 12,66 & & \\
\hline \multirow{4}{*}{ Gender role } & \multirow{2}{*}{ Masculine } & Yes & 7 & 129,28 & 8,82 & \multirow{2}{*}{3,004} & \multirow{2}{*}{,004 } \\
\hline & & No & 76 & 111,21 & 15,63 & & \\
\hline & \multirow{2}{*}{ Feminine } & Yes & 7 & 114,71 & 11,68 & \multirow{2}{*}{1,103} & \multirow{2}{*}{,273 } \\
\hline & & No & 76 & 107,48 & 16,92 & & \\
\hline
\end{tabular}

As shown in Table 1, there was a significant relationship between female athletes with the use of hormones intended to change gender appearance anxiety and masculine gender role $(\mathrm{p}<0.05)$. The average of female athletes using hormone was $45.00 \pm 23.85$ while the average of female athletes not using hormones was $33.14 \pm 12.66$. The masculine gender role was found to be $129.28 \pm 8.82$ in female athletes using hormones and $111.21 \pm 15.63$ in females without hormones. Female athletes using hormones for gender change have been found to have high masculine gender role and appearance anxiety.

Table-2. ANOVA chart between maternal education level and appearance anxiety and gender (feminine-masculine) role in women athletes.

\begin{tabular}{|c|c|c|c|c|c|c|c|c|}
\hline \multicolumn{3}{|c|}{ Variables } & Sum of squares & df & Mean square & $\mathbf{F}$ & $p$ & LSD \\
\hline \multirow{3}{*}{\multicolumn{2}{|c|}{ Appearance anxiety }} & Intergroup & 1281,058 & 2 & 640,529 & \multirow{3}{*}{3,400} & \multirow{3}{*}{,038 } & \multirow{3}{*}{$1-2$} \\
\hline & & In-group & 15069,207 & 80 & 188,365 & & & \\
\hline & & Total & 16350,265 & 82 & & & & \\
\hline \multirow{6}{*}{ Gender role } & \multirow{3}{*}{ Masculine } & Intergroup & 3387,025 & 2 & 1693,513 & \multirow{3}{*}{7,738} & \multirow{3}{*}{,001 } & \multirow{3}{*}{$1-2$} \\
\hline & & In-group & 17509,143 & 80 & 218,864 & & & \\
\hline & & Total & 20896,169 & 82 & & & & \\
\hline & \multirow{3}{*}{ Feminine } & Intergroup & 3275,132 & 2 & 1637,566 & \multirow{3}{*}{6,763} & \multirow{3}{*}{,002 } & \multirow{3}{*}{$1-2$} \\
\hline & & In-group & 19370,097 & 80 & 242,126 & & & \\
\hline & & Total & 22645,229 & 82 & & & & \\
\hline
\end{tabular}

As shown in Table 2, A significant difference was found between the appearance anxiety, feminine gender role, and masculine gender role groups according to maternal education level variable $(p<0.05)$. It was determined that the level of maternal education affected the female anxiety, masculine and feminine gender roles on female athletes.

Table-3. ANOVA chart between the level of education and the appearance anxiety and the gender (feminine-masculine) role of female athletes.

\begin{tabular}{|c|c|c|c|c|c|c|c|c|}
\hline \multicolumn{3}{|c|}{ Variables } & Sum of squares & df & Mean square & $\mathbf{F}$ & $\bar{p}$ & LSD \\
\hline \multirow{3}{*}{\multicolumn{2}{|c|}{ Appearance anxiety }} & Intergroup & 781,669 & 2 & 390,834 & \multirow{3}{*}{2,008} & \multirow{3}{*}{, 141} & \\
\hline & & In-group & 15568,596 & 80 & 194,607 & & & \\
\hline & & Total & 16350,265 & 82 & & & & \\
\hline \multirow{6}{*}{ Gender role } & \multirow{3}{*}{ Masculine } & Intergroup & 1823,063 & 2 & 911,531 & \multirow{3}{*}{3,823} & \multirow{3}{*}{,026 } & \multirow{3}{*}{$1-2$} \\
\hline & & In-group & 19073,106 & 80 & 238,414 & & & \\
\hline & & Total & 20896,169 & 82 & & & & \\
\hline & \multirow{3}{*}{ Feminine } & Intergroup & 132,412 & 2 & 66,206 & \multirow{3}{*}{, 235} & \multirow{3}{*}{, 791} & \\
\hline & & In-group & 22512,817 & 80 & 281,410 & & & \\
\hline & & Total & 22645,229 & 82 & & & & \\
\hline
\end{tabular}

As seen in Table 3, there was a significant difference between the groups according to the paternal education level and the male gender $(p<0.05)$. It has been determined that the level of paternal education affects the masculine gender roles of female athletes. 
Table-4. Correlation table between variables.

\begin{tabular}{|c|c|c|c|c|c|c|}
\hline \multicolumn{3}{|c|}{ Variables } & Age & Sport age & Appearance anxiety & Masculine gender role \\
\hline \multirow{3}{*}{\multicolumn{2}{|c|}{ Appearance anxiety }} & $\mathrm{r}$ &,$- 229^{*}$ &, 110 & & \\
\hline & & $\mathrm{p}$ & ,037 & ,321 & & \\
\hline & & $\mathrm{N}$ & 83 & 83 & & \\
\hline \multirow{6}{*}{ Gender role } & \multirow{3}{*}{ Masculine } & $\mathrm{r}$ &,- 154 & , 139 &, $320^{* *}$ & \\
\hline & & $\mathrm{p}$ &, 164 &, 210 & ,003 & \\
\hline & & $\mathrm{N}$ & 83 & 83 & 83 & \\
\hline & \multirow{3}{*}{ Feminine } & $\mathrm{r}$ &,- 163 & ,031 &, $222^{*}$ &, $546^{* *}$ \\
\hline & & $\mathrm{p}$ &, 141 &, 778 & ,044 & ,000 \\
\hline & & $\mathrm{N}$ & 83 & 83 & 83 & 83 \\
\hline
\end{tabular}

As seen in Table 4, a negative correlation was found between the age variable and appearance anxiety. As age increased, there was a decrease in the scores of appearance anxiety level. A positive relationship was found between appearance anxiety and gender roles. As the anxiety scores of the female athletes increased, the average score of the feminine and masculine gender roles increased.

\section{Discussion and Result}

In the study which examined gender role and appearance anxiety in women athletes except for gender norms; In female athletes, when the hormone-induced appearance anxiety and gender role were examined, a significant difference was found between appearance anxiety and masculine gender role $(\mathrm{p}<0.05)$. The female anxiety and masculine gender role of female athletes using hormones are found to be higher value than those who do not use hormones Table 1. When evaluated in terms of gender roles, masculine gender role is dominant, rational, oppressive, fearless, safe, independent, cold-blooded, strong, solid, aggressive, active and problem-solving skills to be successful while feminine gender role is defined such as loving, emotional, sensitive, moderate, dependent, compassionate, submissive, modest, delicate, caring, passive (Lips, 2008; Dökmen, 2012). Past studies have shown that gender identity is related to sports participation and female participants are mostly androgynous and masculine (Clément-Guillotin and Fontayne, 2011; Hively and El-Alayli, 2014). A significant difference was found between the appearance anxiety, feminine gender role, and masculine gender role groups according to maternal education level variable $(p<0.05)$. It was determined that the level of maternal education affected the female anxiety, masculine and feminine gender roles on female athletes Table 2. The traditional roles of women and men in societies where the education level of women increased and entered the working life started to change in favor of women (Attanapola, 2004). In a study investigating the gender role attitudes of sports workers, there was a significant difference between gender roles and gender, education and parental education. It is noteworthy that the traditional attitude of women's sports workers and the egalitarian attitude values of male sports workers are high (Baştuğ et al., 2017). There was a significant difference between the groups according to the paternal education level and the male gender $(p<0.05)$. It has been determined that the level of paternal education affects the masculine gender roles of female athletes Table 3. Some studies show that there may be changes in the role of gender together with doing sport (Melli, 2000; Gerek, 2015). Mccutcheon and Mitchell (1984) found that female runners tend to have androgynous and masculine tendencies rather than feminine. Gill (1992) showed that female athletes exhibit androgynous properties and also show very low 13-22\% feminine characteristics and female athletes have higher masculine and feminine characteristics compared to non-athletes females (Koca et al., 2005). In this study which investigated the gender role characteristics between elite women athletes and women academics and non-sports women, It was found that elite women athletes have an androgynous role, academician women have masculine role and women who do not do sports have a feminine role (Noyan, 2006). A negative correlation was found between the age variable and appearance anxiety. As age increased, there was a decrease in the scores of appearance anxiety level. A positive relationship was found between appearance anxiety and gender roles. As the anxiety scores of the female athletes increased, the average score of the feminine and masculine gender roles increased Table 4. It has been determined that sport is a factor that increases the level of body perception and gender role in individuals stating that athletes care about health, appearance and physical competence and they are satisfied with body parts due to their muscular body structures developed according to their sports In terms of gender role as well as they have an androgynous personality which can show the feminine and masculine features required by the environment (Baştuğ and Kuru, 2009). In a study that examined the level of self-esteem and appearance of the athletes, it was determined that there was a positive increase in self-confidence and appearance perception values after weight loss in athletes (Bastug et al., 2016). Barlett et al. (2008) reported that pressure from the mass media was related to body satisfaction, body esteem, self-esteem, psychological disorders (e.g., depression) and behavioral outcomes (e.g., excessive exercises). As a result of the studies of Koca et al. (2005). it was found that participation in sports can be determinants of gender roles of individuals and athletes had androgynous and masculine gender roles respectively compared to non-athletes. In the study which examined the relationship between social concerns and gender roles in youth, a significant relationship was found between gender role and appearance anxiety and gender role was determined to decrease the appearance anxiety when femininity and masculinity scores increased (Ülkü, 2017). In the study which investigated the level of loneliness and social anxiety in university students, it was found that women experienced social anxiety more than men and there was a significant difference in age-related anxiety level (Baştuğ et al., 2018). In a study investigating whether sports affect the gender role of women, masculinity and social acceptability characteristics of women who exercise sports are higher than those who do not. There was no difference in the feminine gender role, but it was determined that female athletes exhibited more androgynous characteristics than non-athletes females (Gerek, 2015). These studies support our work.

The female anxiety and masculine gender role of female athletes using hormones are found to be higher value than those who do not use hormones. It was determined that the level of maternal education affected the female anxiety, masculine and feminine gender roles on female athletes. It has been determined that the level of paternal 
education affects the masculine gender roles of female athletes. In female athletes, it has been determined that as the age increases, the appearance anxiety decreases and when appearance anxiety rises, feminine and masculine gender roles rise. It is recommended that special contact with women athletes who go beyond the social gender norms should be established according to expert opinions and all actors such as sports managers, trainer, sportsman, referee, physical education teacher should be informed. To increase the proportion of women engaged in sports in the society, to support the girls who are new to the sports and not to create false opinions about the sportswomen, it is recommended to put forward the role models suitable for the female athlete profile.

\section{References}

Attanapola, C.T., 2004. Changing gender roles and health impacts among female workers in export-processing industries in Sri Lanka. Social Science \& Medicine, 58(11): 2301-2312.Available at: https://doi.org/10.1016/j.socscimed.2003.08.022.

Barlett, C.P., C.L. Vowels and D.A. Saucier, 2008. Meta-analyses of the effects of media images on men's body-image concerns. Journal of Social and Clinical Psychology, 27(3): 279-3 10.Available at: https://doi.org/10.1521/jscp.2008.27.3.279.

Baştuğ, G., 2011. The study of athletes' body perception and gender role. Collegium Antropologicum, 35(4): 1037-1043.

Baştuğ, G., İ. Günel and E. Bingöl, 2017. Attitudes of sports employees related to gender roles. European Journal of Physical Education and Sport Science, 3(12): 563-574.

Baştuğ, G. and E. Kuru, 2009. A research about the perception levels of their bodies of female athletes and gender roles, Gazi University. Gazi Education Faculty Journal, 29(2): 533-555.

Bastug, G., M. Özdemir, H. Tanir and E. Salim, 2016. The effect of acute weight loss on body composition, self-esteem and appearance esteem before competitions. Journal of Education and Training Studies, 4(11): 206-212.Available at: https://doi.org/10.11114/jets.v4i11.1732.

Baştuğ, G., I. Uçar and T. Yılmaz, 2018. Investigation of the level and social anxiety level of the individuals in the recreation activities. Social Sciences Studies Journal, 4(19): 1974-1982.Available at: https://doi.org/10.26449/sssj.587.

Bem, S.L., 1974;1975. The measurement of psychological androgyny. Journal of Consulting and Clinical Psychology, 42(2): $155-162$.

Bhasin, K., 2003. Gender uploaded the roles loaded on us. Solidarity with Women Foundation Publications. pp: 55-61.

Cherry, A.L., 2005. Examining global social welfare issues. Belmont: ThomsonBrooks/Cole.

Clark, D. and A. Wells, 1995. A cognitive model of social phobia. Social phobia: Diagnosis, assessment and treatment. Rumination And Negative Appraisal In Social Phobia. In, Heimberg RG, Liebowitz MR, Hope DA, Schneier FR (editors.). New York: Guilford Press. pp: 143-59.

Clément-Guillotin, C. and P. Fontayne, 2011. Situational malleability of gender schema: The case of the competitive sport context. Sex Roles, 64(5-6): 426-439.Available at: https://doi.org/10.1007/s11199-010-9912-1.

Dogan, T., 2010. Turkish adaptation of the social appearance anxiety scale: A study of validity and reliability. Hacettepe University Faculty of Education Journal, 39: 151-159.

Dökmen, Z., 1991. The Turkish version of the Bern sex role inventory. Kriz Dergisi, 7(1): 27-40.

Dökmen, Z., 2004. Gender social psychological explanation. Ankara: System Publisher. pp: 20-29.

Dökmen, Z.Y., 2012. Gender: Social psychological explanations. Istanbul: Remzi Bookstore.

Gerek, Z., 2015. Comparison of communal sex roles of female sports students studying in different universities in Turkey. Educational Research and Reviews, 10(5): 541-546.Available at: https://doi.org/10.5897/err2014.2036.

Gill, D.L., 1992. Gender and sport behaviour. In T.S Horn (Ed.), Advances in sport psychology. Champaing: Human Kinetics. pp: 143-160.

Hart, T.A., D.B. Flora, S.A. Palyo, D.M. Fresco, C. Holle and R.G. Heimberg, 2008. Development and examination of the social appearance anxiety scale. Assessment, 15(1): 48-59.Available at: https://doi.org/10.1177/1073191107306673.

Harter, S., 1983. Handbook of child psychology: Socialization, personality and social development. Developmental perspectives on the selfsystem. In Heatherington EM (editor). New York: Wiley, 275- 386.

Hively, K. and A. El-Alayli, 2014. You throw like a girl: The effect of stereotype threat on women's athletic performance and gender stereotypes. Psychology of Sport and Exercise, 15(1): 48-55.Available at: https://doi.org/10.1016/j.psychsport.2013.09.001.

Imamoĝklu, E.O. and Z. Karakitapoĝklu-Aygüun, 2004. Self-construals and values in different cultural and socioeconomic contexts. Genetic, Social, and General Psychology Monographs, 130(4): 277-306.Available at: https://doi.org/10.3200/mono.130.4.277-306.

Imamoğlu, E.O. and Z. Karakitapoğlu-Aygün, 2006. Actual, ideal, and expected relatedness with parents across and within cultures. European Journal of Social Psychology, 36(5): 721-745.Available at: https://doi.org/10.1002/ejsp.313.

Kavasoğlu, İ. and M. Yaşar, 2016. The athletes beyond gender norms. Hacettepe Journal of Sport Sciences, 27(3): 118-132.

Kavuncu, A.N., 1987. Adaptation of Bem gender role inventory to Turkish society. Unpublished Master's Thesis, Hacettepe University, Ankara.

Kleindienst-Cachay, C. and K. Heckemeyer, 2008. Women in male domains of sport. International Journal of Eastern Sports \& Physical Education, 6(1): 14-37.

Koca, C., 2006. Gender relations in physical education and sport. Hacettepe Journal of Sport Sciences, 17(2): 81-99.

Koca, C., F.H. Aşçi and S. Kirazcr, 2005. Gender role orientation of athletes and nonathletes in a patriarchal society: A study in Turkey. Sex Roles, 52(3-4): 217-225.Available at: https://doi.org/10.1007/s11199-005-1296-2.

Koca, C. and G. Demirhan, 2005. Gender reproduction process in the field of physical education and sport. Hacettepe Journal of Sport Sciences, 16(4): 200-228.

Leary, M.R., R.M. Kowalski and C.D. Campbell, 1988. Self-presentational concerns and social anxiety: The role of generalized impression expectancies. Journal of Research in Personality, 22(3): 308-32 1.Available at: https://doi.org/10.1016/0092-6566(88)90032-3.

Lips, H.M., 2008. Sex and gender: An introduction. 6th Edn., Boston: McGraw-Hill.

Mayer, F.S. and K. Sutton, 1996. Personality: An integrative approach. New Joursey: Prentice Hall.

Mccutcheon, L. and M. Mitchell, 1984. The prediction of running-related attitudes and behaviors from the androgynous model. Wellness Perspectives, 1: 31-34.

Melli, N., 2000. Karşılaştırıl comparison of the gender roles of women and men who do sports and individual and team sports. Science Thesis H.Ü Health Sciences.

Noyan, I., 2006. Gender role properties comparison of elite women athletes and academics women with non-athlete's women. Ankara University, Department of Physical Education and Sports, Master Thesis, Ankara.

Ozcan, H., B. Subasi, B. Budak, M. Çelik, S.C. Gürel and M. Yildiz, 2013. Relationship between self-esteem, social appearence anxiety, depression and anxiety in adolescent and young adult women. Journal of Mood Disorders, 3(3): 107-113.Available at: https://doi.org/10.5455/jmood.20130507015148.

Sancar, S., 2013. Masculinity. Gender studies. Eskisehir: Anadolu University Publications. pp:168-191.

Ülkü, H., 2017. The relationship between social appearance anxiety andsocial anxiety in youth in the context of social gender. Uskudar University, Social Sciences Institute, Master Thesis, İstanbul.

Yousefi, B., Z. Hassani and O. Shokri, 2009. Reliability and factor validity of the 7-item social physique anxiety scale (SPAS-7) among university students in Iran. World Journal of Sport Sciences, 2(3): 201-204. 